\title{
A Pragmatic Multi-Method Investigation of Discrepant Technological Events: \\ Coping, Attributions, and 'Accidental' Learning
}

\author{
Ana Ortiz de Guinea \\ Department of Information Technology \\ HEC Montréal \\ 3000, chemin de la Côte-Sainte-Catherine \\ Montréal, Québec \\ Canada H3T 2A7 \\ Tél: $\underline{514-340-7817}$ \\ Fax: 514-340-6132 \\ E-mail: ana.ortiz-de-guinea@hec.ca
}

Please cite as :

Ortiz de Guinea, A., \& Raymond, L. (2020). Enabling Innovation in the Face of Uncertainty through IT Ambidexterity: A fuzzy set Qualitative Comparative Analysis of Industrial Service SMEs. International Journal of Information Management, 50, pp. 244-260. ISSN: 0268-4012.

Ana Ortiz de Guinea is an associate professor in the Department of Information Technology of HEC Montréal. She received her Ph.D. in Management from Queen’s University. Her research interests include the use of Information Systems by individuals and organizations. Her work has been published in numerous journals, such as Computers in Human Behavior, Information \& Management, the International Journal of E-Collaboration, The International Journal of Human Resource Management, the International Journal of Medical Informatics, the Journal of the Association for Information Systems, the Journal of Global Information Systems, the Journal of Management Information Systems, and MIS Quarterly. 


\title{
A Pragmatic Multi-Method Investigation of Discrepant Technological Events: Coping, Attributions, and 'Accidental' Learning
}

\begin{abstract}
Discrepant technological events or situations that entail a problem, a misunderstanding or a difficulty with the Information Technology (IT) being employed, are common in the workplace, and can lead to frustration and avoidance behaviors. Little is known, however, about how individuals cope with these events. This paper examines these events by using a multimethod pragmatic approach informed by coping theory. The results of two studies - a critical incident study and an experiment - serve to build and test, respectively, a theoretical model that posits that individuals use a variety of strategies when dealing with these events: they experience negative emotions, make external attributions, and adopt engagement coping strategies directed at solving the event, eventually switching to a disengagement coping strategy when they feel they have no control over the situation. Furthermore, users' efforts may result in 'accidental' learning as they try to overcome the discrepant IT events through engagement coping. The paper ends with a discussion of the results in light of existing literature, future opportunities for research, and implications for practice.
\end{abstract}

Keywords: use, usage, errors, technology, learning, events, attribution, coping, emotion, frustration, technostress. 


\section{INTRODUCTION}

When computers are used daily by almost every employee in an organisation, even a minor technical problem can cost thousands of dollars in lost productivity unless dealt with quickly [56,

p. 100].

Magazines include tips on how to deal with technological interruptions [Professional

Manager, 1], IT managers describe instances of shattered monitors and other broken technologies as a result of 'technology rage' [59], and employees report that many of their IT interactions are wasted on frustrating experiences [46]. Studying such experiences is important not only due to productivity losses but because they add up over time and influence future IT continuance decisions [10, 14, 16], extended IT use [67], and well-being through technostress [77].

Difficulties with IT can arise from discrepant IT events, that is, those occurring when an IT interaction does not match one's expectations [7, 38, 63]. A discrepant IT event occurs when a technology does not behave according to plan or when a user cannot make the application do what s/he wants it to do while working on a work-related task [9, 63]. Despite their prevalence [e.g., 46], little is known about the processes by which people deal with discrepant IT events.

As a result, this paper investigates the following research question: how do users cope with discrepant IT events? In order to address this question, we take a pragmatic approach using both deductive and inductive theorizing [72]. First, we review literature that informs our research in a deductive way, using coping theory to draw conclusions about how users deal with discrepant IT events. Second, we refine these conclusions with the inductive analysis of data from a critical incident study. Drawing on study findings, as well as other theoretical perspectives (attributions and accidental learning), we then develop theoretical propositions. Finally, the resulting model is validated with an experiment. 
This paper contributes to the literature in several ways. It demonstrates how certain processes that are believed to occur before the coping responses start, such as deciding if a situation is changeable, actually take place after individuals have engaged in coping responses aimed at overcoming the situation. Furthermore, the results demonstrate that learning is not the exclusive outcome of formal intentional efforts as most of the literature implies but can result 'accidentally' as a byproduct of the coping process. Finally, by studying discrepant IT events, our research addresses recent calls for studies concerning the direct effects of technology on triggering users' behaviors [62].

The remainder of the paper is organized as follows. First, we present a review of coping theory as it applies to users' adaptational responses to discrepant IT events. Second, we report on a critical incident study, along with the development of theoretical propositions that draw not only on study findings but on coping, attributional, and learning theories. Third, we describe an experiment which serves to corroborate the temporal sequence implied in the developed propositions. Finally, the article ends with a discussion of this paper's contributions to theory and practice, as well as future opportunities for research.

\section{THEORETICAL DEVELOPMENT}

Using a behavioral approach, IT use has been defined as a person's interaction behaviors, including the activities performed to adapt and modify the technological context in which the task takes place [4]. Therefore, this perspective on IT use includes adaptations to discrepant IT events. Interestingly, it overlaps with the notion of adaptational responses to the environment found in coping theory: coping theory represents an adaptational cognitive and behavioral effort to manage relations with the environment [49]. More specifically, coping can be defined as individuals' cognitive and behavioral efforts to adapt and deal with specific environmental 
demands that generate emotional discomfort (e.g., stress) [30]. As a result, coping theory appears to be a good fit from which to start analyzing the process by which users adapt and deal with discrepant IT events.

In general, IT research on coping is quite scarce. A notable exception is research by Beaudry and Pinsonneault [7, p. 496] who conceptualized coping as user adaptation, or "the cognitive and behavioral efforts exerted by users to manage specific consequences associated with a significant IT event that occurs in their work environment”. Although there are many IS papers that cite coping theory, an examination of these papers shows that most of them refer to coping in the discussion section [e.g., 43], or to justify a relation between variables without actually examining coping [e.g., 51]. The few papers that apply coping theory have been aimed at studying employees' coping processes when: a new IT is introduced in the work setting [e.g., $6,7,21,36]$; users avoid malicious IT [e.g., 52, 54]; or users from different countries deal with rapid technological change [e.g., 25]. In contrast, little research has been directed at ways in which users cope with the technology once it has been adopted and is being [see 63 for an exception].This is somewhat surprising because a considerable amount of research in IS has been directed towards negative reactions [e.g., computer anxiety, 15] to technology and coping provides an appropriate theory from which to examine them.

\section{Coping Theory and Discrepant IT Events}

During interactions between individuals with their environments, there are two appraisals that occur concurrently when an event takes place: primary and secondary appraisals [49]. During primary appraisals, individuals map an event with its potential consequences for their well-being: 1) negative if the event is perceived as threatening; 2) positive if the event is seen as 
improving well-being; and 3) irrelevant if the event is perceived as neutral [49]. Negative events generate stress, or the emotional state resulting from an imbalance between demands by the environment and individuals' resources [49]. Stress is seen as a precondition for coping responses to take place. That is, the coping process starts when an event is perceived as 'negative' for well-being and thus generates stress [49]. Because discrepant IT events correspond to difficulties, problems, and misunderstandings with the IT being employed [80], they can be seen as a particular case of the negative events that trigger the coping process.

During secondary appraisals, individuals assess the resources available to alter the negative event or situation [49]. These resources refer to what is at one's disposal for dealing with the situation rather than to the actual way in which individuals deal with the event [65]. The two concurrent appraisals prepare individuals for action in the form of different coping responses [49, 69].

The literature on coping has identified a wide variety of coping responses [see 73]. For example, Skinner et al. [73] reviewed over 100 assessments of coping and found over 400 labels used to describe categories of coping. Among the most widely recognized categories of coping are those of engagement/disengagement $[13,35]$ and problem-focused/emotion-focused coping $[47,49,65]$. In this paper, we will use the former approach rather than the later for two main reasons. First, the engagement/disengagement categories are exclusive distinctions whereas the problem-focused/emotion-focused are not [11, 48], and thus, predictions about the latter are often unclear. Second, it has been argued that the problem-focused/emotion-focused categories are hard to evaluate and some factor analysis studies have been unable to support them [55, 73]. Finally, the engagement/disengagement categories represent the coping process well in real life [11]. 
In general, if users appraise the discrepant IT event as changeable (they feel they have the necessary resources to change it), they are more likely to adopt engagement coping [28, 50]. Engagement strategies encompass what has traditionally been labeled as problem-focused and some instances of emotion-focused coping: they are coping mechanisms directed to managing the event that is the source of the discomfort, or the negative emotions that result from the event [11]. They entail a wide range of activities: such as trial-and-error, gathering information, and help-seeking activities [35]. All in all, engagement coping encompasses responses directed towards the modification of the negative situation through the elimination or alteration of the very source of negative discomfort [13, 65] (see Figure 1).

\section{Figure 1. Application of Coping Theory to Discrepant IT Events}

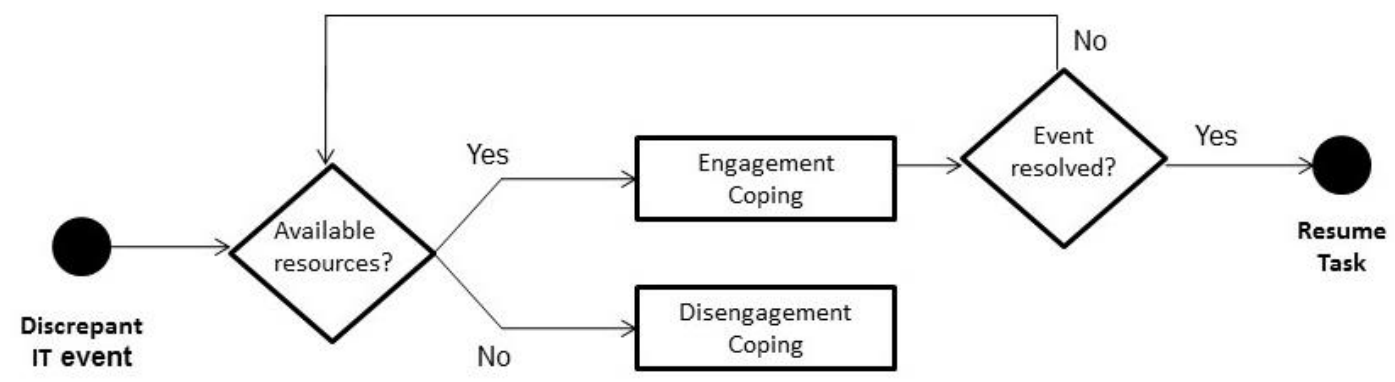

In contrast, when individuals think they cannot do anything to change a situation (i.e., they do not have the necessary resources), they will use escape coping (disengagement strategies) [28, 50]. Disengagement coping encompasses strategies that are directed towards escaping from the negative situation or the negative feelings that the situation generates [11]. That is, during disengagement coping, behavioral and cognitive efforts are no longer aimed at overcoming the situation; rather, they are concerned with some other activity that provides distraction from the negative emotion [35]. In the case of discrepant IT events, disengagement coping may entail 
users resuming the task they were addressing before the discrepant IT event occurred, or if the event is fatal and prevents them from doing so, engaging in other tasks unrelated to the event.

There are two fundamental characteristics of coping. First, coping is a dynamic process, meaning that its focus is on the explanation of the person's behaviors and thoughts as well as on how these change as the situation unfolds over time [30]. Second, coping is contextual: each person subjectively evaluates the encounter with the environment and the available resources to manage it [30]. In summary, coping entails a dynamic interaction between a person and the event including attention to how circumstances and behaviors change as the situation develops [12]. As a result, coping is modified and adjusted as the potentially harmful encounter unfolds: after the coping mechanism has been executed, there is a reappraisal of the person-environment relationship, and new coping mechanisms can be put into place (see Figure 1) [12, 49].

In summary, coping theory provides an explanation regarding how users deal with discrepant IT events. Because discrepant IT events represent a specific contextual case of the general 'negative events' explained by coping theory, an exploratory study is presented next to fine-tune the conclusions drawn from the theory.

\section{STUDY 1: CRITICAL INCIDENT STUDY}

Consistent with an inductive pragmatist approach in which an initial understanding of coping theory is given a priori and it is refined a posteriori with empirical data [72], we used a critical incident methodology [27]. This technique requires the collection, analysis, and interpretation of participants' responses to a certain incident [27]. The critical incident technique is a well-established methodology that has been used successfully in different disciplines such as human-computer interaction [e.g., 71]. 
This technique is appropriate for a number of reasons. First, because coping theory has been rarely used in IS, the critical incident method allows us to 'discover' new insights and further develop theory, coherent with the tenets of the inductive pragmatic model [72]. Second, this method allows for the direct experience of discrepant IT events by participants in workrelated environments without the mediation of artificial explanations of situations. Finally, researchers have argued for the necessity to ask for narratives to better study coping processes and mechanisms [47] and the critical incident method allows us to do so.

Following the guidelines for applying this technique, a questionnaire was designed in which participants were asked to identify a discrepant IT event they had recently experienced (i.e., in the past two weeks) in order to minimize retrospective bias [34]. After they identified the event, following the recommendations of Lazarus [47], participants were asked to provide a description of the event as well as their feelings, thoughts, and behaviors as the event unfolded..

The questionnaire was administered to organizational employees through the Study Response Project at Syracuse University, New York. The Study Response project is a non-profit organization which aims is to facilitate online research for behavioral, social and organizational researchers by distributing mail participation requests to adult participants. Study Response has been used previously in management, psychology, and MIS research [e.g., 66]. In total, we captured 217 usable descriptions of discrepant IT events.

\section{Coding and Analyses}

Once the data were collected, we proceeded with the coding. A coding sheet was developed based on coping theory, including the two main categories of coping, engagement and disengagement [13]. Within each category of coping, there were subthemes. For example, subthemes of engagement coping are: active coping, which means taking active steps to try to 
remove or circumvent the event or to ameliorate its effects, and help seeking behaviors, such as looking for instrumental support $[13,35]$. Because coping theory also deals with negative emotions [74], we also coded for 'negative emotions' and several subcategories of these, such as stress and frustration. Finally, because the objective of the study is to fine-tune coping theory to the specific case of discrepant IT events, other categories emerged from the data and were added to the coding sheet.

It makes sense that more severe discrepant event situations might have stronger or more dramatic consequences. As a result, each discrepant event was categorized as low, moderate, or severe. For example, a low discrepant event could be a formatting nuisance, a moderate discrepant event could be specific instances of the technology crashing, and a high discrepant event could be losing the work of several hours or days.

The author and an independent rater coded a subset of the data. If there was a disagreement, the two coders would discuss the coding and resolve the issue. This was done iteratively until the two coders reached an inter-rater agreement of .86. After this, the independent rater coded the rest of the data.

It is important to note that quotes were not exclusive of a coding theme or category. That is, the same case could be assigned to different categories and themes. Furthermore, coding theoretical saturation was met: no new themes were identified in the critical incident study after the first 60 cases.

The main unit of analysis was discrepant IT events. As a result, interactions were analyzed first within individuals and then across individuals [20]. This cross-case analysis was aimed at counteracting the human tendency to leap to conclusions based on limited data or the influence of vivid respondents $[18,20]$. We analyzed the data in an inductive way so that the 
theoretical framework presented earlier would not constrain further theoretical development. As a result, in order to develop propositions, we intertwine the empirical evidence with both coping theory and new theoretical perspectives next.

\section{Results}

A total of 217 individuals provided usable responses to the survey (see Table 1 for demographics): $27.1 \%$ were between 30 and less than 40 years old; $53.5 \%$ were female; most had more than 10 years of work experience; and the majority had used the software for which they reported a recent discrepant event for over one year (and utilized it frequently: more than 8 hours per week and several times per day).

Table 1. Critical Incident Study: Demographics

\begin{tabular}{|c|c|c|}
\hline & & Percentage \\
\hline \multirow[t]{6}{*}{ Age } & $<20$ years & 0 \\
\hline & $20-<30$ years & 26.6 \\
\hline & $30-<40$ years & 27.1 \\
\hline & $40-<50$ years & 23.4 \\
\hline & $50-<60$ years & 19.7 \\
\hline & 60 years or more & 3.2 \\
\hline \multirow[t]{2}{*}{ Gender } & Male & 46.5 \\
\hline & Female & 53.5 \\
\hline \multirow[t]{4}{*}{ Education } & High School Diploma & \\
\hline & Some College / University & \\
\hline & Graduate Degree & \\
\hline & Other & \\
\hline \multirow{6}{*}{$\begin{array}{l}\text { Overall work } \\
\text { experience }\end{array}$} & $<1$ year & 3.7 \\
\hline & $1-<5$ years & 16.6 \\
\hline & $5-<10$ years & 17.1 \\
\hline & $10-<15$ years & 19.7 \\
\hline & $15-<20$ years & 10.1 \\
\hline & $20-<25$ years & 10.6 \\
\hline $\begin{array}{l}\text { Overall work } \\
\text { experience }\end{array}$ & 25 years or more & 22 \\
\hline \multirow{4}{*}{$\begin{array}{l}\text { Experience at } \\
\text { current job } \\
\text { position }\end{array}$} & $<1$ year & 15.2 \\
\hline & $1-<3$ years & 29.8 \\
\hline & $3-<5$ years & 16.5 \\
\hline & $5-<10$ years & 18.3 \\
\hline Experience at & $10-<15$ years & 8.3 \\
\hline
\end{tabular}




\begin{tabular}{|c|c|c|}
\hline $\begin{array}{l}\text { current job } \\
\text { position }\end{array}$ & 15 years or more & 11.5 \\
\hline \multirow{2}{*}{$\begin{array}{l}\text { Experience with } \\
\text { software }\end{array}$} & $<3$ months & 8.7 \\
\hline & $3-<6$ months & 4.6 \\
\hline \multirow{3}{*}{$\begin{array}{l}\text { Experience at } \\
\text { current job } \\
\text { position }\end{array}$} & $6-<12$ months & 7.3 \\
\hline & $1-<2$ years & 11.9 \\
\hline & 2 years or more & 66.5 \\
\hline \multirow{2}{*}{$\begin{array}{l}\text { Use of software } \\
\text { per week }\end{array}$} & $<1$ hour & 12.8 \\
\hline & $1-<2$ months & 10.1 \\
\hline \multirow{3}{*}{$\begin{array}{l}\text { Experience at } \\
\text { current job } \\
\text { position }\end{array}$} & $2-<3$ hours & 12.4 \\
\hline & 3- $<8$ hours & 19.3 \\
\hline & 8 hours or more & 45.4 \\
\hline \multirow{2}{*}{$\begin{array}{l}\text { Use of software } \\
\text { per month }\end{array}$} & once (or less) a month & 2.3 \\
\hline & a few times a month & 3.7 \\
\hline \multirow{3}{*}{$\begin{array}{l}\text { Experience at } \\
\text { current job } \\
\text { position }\end{array}$} & a few times a week & 16.1 \\
\hline & about once a day & 12.4 \\
\hline & several times per day & 65.4 \\
\hline
\end{tabular}

Results are organized by immediate responses (engagement coping, negative emotions, and attributions), the dynamicity of the coping process, and 'accidental' outcomes. Table 2 presents the propositions that are developed below, along with sample quotes from the participants.

\section{Immediate Responses to Discrepant IT Events}

According to the findings, there are three main immediate responses to discrepant IT events: engagement coping, negative emotions, and attributions. Evidence of these responses along with their theoretical explanations are given next.

\section{Engagement Coping}

As explained earlier, coping theory suggests that during secondary appraisal users evaluate whether they feel they have the resources (or control) to change the situation [49, 65]. This appraisal is instrumental in deciding which coping strategy to adopt for a given situation (see Table 2) $[49,69]$. However, our results demonstrate that individuals appear not to know whether they have control over the situation until later. That is, immediately after the discrepant IT event takes place, they try to overcome the event adopting an engagement coping strategy which allows them 
Table 2. Critical Incident Study: Chains of Evidence

\begin{tabular}{|c|c|c|}
\hline & Propositions & Sample Quotes \\
\hline \multirow{7}{*}{ 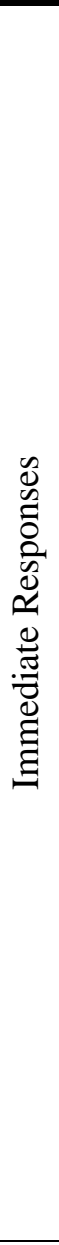 } & \multirow[t]{4}{*}{$\begin{array}{l}\text { P1: When there is a } \\
\text { discrepant IT event, } \\
\text { users adopt an } \\
\text { engagement coping } \\
\text { strategy }\end{array}$} & $\begin{array}{l}\text { I composed a somewhat lengthy memo in regards to a meeting with my district manager, this memo was to be sent to all } \\
\text { the other store managers, and assistant managers in our district. After completing the memo I saved it into My } \\
\text { Documents to send out later. After about } 1 \text { hour I attempted to open the file but could find no record of it. I proceeded to } \\
\text { search in all other areas of the application but could not find the memo, I even signed off then back on but the memo was } \\
\text { gone. ... I had to re-type the memo which cost me an hour of my day. (Participant 400) }\end{array}$ \\
\hline & & $\begin{array}{l}\text { The secure access to the database is too secure - it won't let me on with my own user ID and password if I am not on the } \\
\text { exact computer and browser I signed up with. This means I cannot access the database from my laptop or while } \\
\text { travelling. I also cannot test it as I had planned with different browsers. I tried several steps to retrieve my user ID and } \\
\text { password on other computers and get the system to recognize me, to no avail. I reported the problem to the agency, but } \\
\text { nothing has been done. I will have to go to their offices to test the database, which is not how it is supposed to work } \\
\text { (Participant 178) }\end{array}$ \\
\hline & & $\begin{array}{l}\text { After my company upgraded to MS Office } 2003 \text { just a few months ago, I discovered that 'copying' text, and then 'pasting' } \\
\text { it into MS Word, would cause Word to hang, or lock up. After trying multiple times, under various situations, I found } \\
\text { that it happened only when the 'copied' data contained a web page link. I then emailed Microsoft about my problem, and } \\
\text { within } 3 \text { days had an answer that worked. (Participant } 62 \text { ) }\end{array}$ \\
\hline & & $\begin{array}{l}\text { For example, every time I get a report from our sub office, it defaults from English to French. I do my best to try and } \\
\text { remember all the fixes I have found [...] I also found an excellent mentor in the office who has helped me tremendously } \\
\text { (Participant 59) }\end{array}$ \\
\hline & \multirow{3}{*}{$\begin{array}{l}\text { P2: When there is a } \\
\text { discrepant IT event, } \\
\text { user experience } \\
\text { negative emotions }\end{array}$} & $\begin{array}{l}\text { I found annoying the autoformatting features, I wanted to do something differently from Word automatism. I tried to } \\
\text { override deleting and going back to do it my way. I felt greatly irritated. (participant 44) }\end{array}$ \\
\hline & & $\begin{array}{l}\text { I was very frustrated and upset. I couldn't get my work done. I was ready to throw the whole computer out the window } \\
\text { (participant 215). }\end{array}$ \\
\hline & & $\begin{array}{l}\text { I was frustrated and irritated at the complexity of the problem. The software was not designed for a beginner such as } \\
\text { myself and with the project due within hours, I was unable to fathom what steps to take to accomplish my task } \\
\text { (Participant } 312 \text { ) }\end{array}$ \\
\hline
\end{tabular}


Table 2. Continued

\begin{tabular}{|c|c|c|}
\hline & Propositions & Sample Quotes \\
\hline \multirow{3}{*}{ 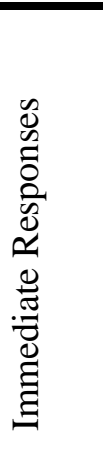 } & \multirow{3}{*}{$\begin{array}{l}\text { P3: When there is a } \\
\text { discrepant IT event, } \\
\text { users will engage in } \\
\text { attribution } \\
\text { assignation, mainly } \\
\text { in external } \\
\text { attributions }\end{array}$} & $\begin{array}{l}\text { [Outlook Express] does not send messages, I do not why, and I have tried everything. Computers never work well } \\
\text { (Participant 308) }\end{array}$ \\
\hline & & $\begin{array}{l}\text { The "hide" and "unhide" functions do not work properly at times [...]I felt quite a bit irritated and tense that work was } \\
\text { getting held up for no fault of mine (Participant 308) }\end{array}$ \\
\hline & & $\begin{array}{l}\text { The bullets would not go in the spot that I wanted them to. It kept moving my entire paragraph over and then it would } \\
\text { erase everything if I removed the bullet, and I just went on like this for a while. I decided to list the info in a different } \\
\text { way. I am frustrated. Upset. Ready to close the program and start again later. Why couldn't this simple direction work } \\
\text { properly. Or maybe it was me who couldn't work it properly and I should know how to do this, right? It should be easy. } \\
\text { What the heck is going on here! (Participant 328) }\end{array}$ \\
\hline \multirow{2}{*}{ 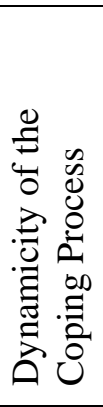 } & \multirow{2}{*}{$\begin{array}{c}\text { P4: When the } \\
\text { discrepant IT event is } \\
\text { not resolved and } \\
\text { users feel they have } \\
\text { the resources to deal } \\
\text { with the event, users } \\
\text { will adjust their } \\
\text { engagement coping }\end{array}$} & $\begin{array}{l}\text { One day the program just could not be entered due to power failure which I thought at the time was a computer glitch. } \\
\text { The first thing I tried was totally shutting down the program and restarting it. It didn't work., next, I went online with live } \\
\text { support to help me solve the problem and was informed that it was a connection problem, so I contacted my ISP and was } \\
\text { told that they were experiencing technical difficulties (Participant 167) }\end{array}$ \\
\hline & & $\begin{array}{l}\text { Microsoft word tries to intercept or change what I am trying to type. For example, I will be using tabs, but only } \\
\text { occasionally, the program puts the tabs on automatically, and when I try to correct the problem, most of the time all the } \\
\text { work that I have just done gets erased [...] I hate this bloody computer, I hate everything it bloody does. At least with a } \\
\text { manual typewriter, the mistakes you made, were your own, not the computer's (Participant 292) }\end{array}$ \\
\hline
\end{tabular}


Table 2. Continued

\begin{tabular}{|c|c|c|}
\hline & Propositions & Sample Quotes \\
\hline \multirow{3}{*}{ 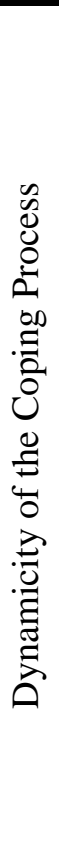 } & \multirow{3}{*}{$\begin{array}{l}\text { P5: When the } \\
\text { discrepant IT event is } \\
\text { not resolved and } \\
\text { users feel they do not } \\
\text { have the resources to } \\
\text { deal with the event, } \\
\text { users will adopt } \\
\text { disengagement } \\
\text { coping. }\end{array}$} & $\begin{array}{l}\text { With Windows } 2000 \text { I had a lot of trouble with the software shutting down unexpectedly several times a day, so I was } \\
\text { forced to save my files after very entry I made. I contacted several computer specialists who tried to hold by installing } \\
\text { service packs a.o., but without effect. Finally I decided to go back to Windows NT until Microsoft solves its problem. I was } \\
\text { horrified the first time: all work gone. But it became easier as time went by and no real solution could be found. I thought I } \\
\text { better stop working for today, go home and don't touch anything for today. (Participant 382) }\end{array}$ \\
\hline & & $\begin{array}{l}\text { Last week the server was down. We were not able to connect to internet or to our district's website. There was nothing we } \\
\text { could do. Being at work during this time was like sitting on my sofa without anything to do to stimulate my mind and at the } \\
\text { same time drawing a paycheck. The reason we were unable to get any work done was not because we are incapable of } \\
\text { paper and pencil task, but more because our jobs have moved along with technology. The work we do is often uploaded } \\
\text { unto our district website, which also contains all pertinent information regarding our district. Even though we do save our } \\
\text { work to disk, to continue the work were we left off often requires us gaining additional information from the website. If the } \\
\text { website is down, which by the way also keeps us from internet access, no work can be done. Well, there was nothing I } \\
\text { could do. After about } 20 \text { minutes of useless effort to at least connect to the internet on a land line without going through } \\
\text { the district's connection, I gave up and resorted to researching } 500 \text { student files. I did not get very far though. The time it } \\
\text { took me to review information in } 50 \text { files is equivalent to the amount of time I could have completed all students files on the } \\
\text { computer (Participant 130) }\end{array}$ \\
\hline & & $\begin{array}{l}\text { I tried to open a document I really needed, but was unable to open it. I tried to download a trial version of Microsoft Office } \\
2007, \text { but it took it forever, then I was only able to download } 12 \% \text { of it within } 12 \text { hours I finally gave up trying to download } \\
\text { this (Participant 380) }\end{array}$ \\
\hline \multirow{3}{*}{ 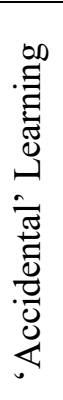 } & \multirow{3}{*}{$\begin{array}{l}\text { P6: When there is } \\
\text { engagement coping, } \\
\text { learning can take } \\
\text { place. }\end{array}$} & $\begin{array}{l}\text { I get frustrated when I can't remember certain functions steps or keys [...] I dug up my manual and hunted for the answer } \\
\text { and found other neat shortcuts in the process (Participant 41) }\end{array}$ \\
\hline & & $\begin{array}{l}\text { I thought that we must input the doctor's license or MMIS\# only. This was causing much frustration due to the fact that on } \\
\text { the fax requests that I work, they don't always include the correct license or MMIS\#. [...] I shared my frustration with a } \\
\text { co-worker and she in turn showed me how to do the name search [...] A co-worker was the one who pointed out that the } \\
\text { search can be done by the name for all clients except NY (Participant 467) }\end{array}$ \\
\hline & & $\begin{array}{l}\text { When trying to clone a section of a picture, the clone stamp won't 'stick' where I tell it to. [...] I was trying to find ways } \\
\text { around this problem but I couldn't come up with anything until I figured out about the zooming. [...] After a few tries I } \\
\text { found that if I zoom in on the picture, the clone stamp will pick up the spot I select (Participant 324) }\end{array}$ \\
\hline
\end{tabular}


to gather more information about the situation, eventually realising whether they can do anything about it.

In the overwhelming majority of cases (94.04\%), participants adopted an engagement coping strategy immediately after the discrepant IT event occurred. Engagement coping strategies, as explained before, are responses directed towards the modification of the negative situation through the elimination or alteration of the very source of negative discomfort [13, 65], in which users fix their attention on the discrepant event [13]. For example, a participant reported how s/he dealt with a problem by switching software: "Some regional languages fonts were not working properly in this software in the past [referring to Microsoft Word]. I used another software" (Participant 381). More evidence of these engagement coping responses is given in Table 2. It is important to point out that users appear to apply an engagement coping strategy regardless of the severity of the event. That is, the automatic response is to try to fix/deal with the situation, whether it is a nuisance or a more serious (even fatal) discrepant event. As a result, users appear to always adopt an engagement coping strategy before appraising whether they have the necessary resources to resolve the event. This may be for two main reasons. First, discrepant situations, regardless of their severity, are motivationally incongruent: that is, they represent a situation that is inconsistent with one's current goals (i.e., the accomplishment of a work-related task) [74]. Second, discrepant IT events can be ambiguous (or are perceived as ambiguous): it is often not clear to the user what he has to do next, whether he has the skills (or other resources) to resolve the encounter, nor can he predict its time duration and impact (see Table 2). Ambiguous events trigger engagement coping responses because they do not give enough evidence of whether individuals have the resources to change the situation [49]. Thus, because of the ambiguity they bring, discrepant IT events trigger engagement coping responses. 
Among the different engagement coping responses that discrepant events trigger, active coping, or taking active steps to overcome the event and directing action and efforts to solve the situation is the most prevalent (88.30\%). Again, the ambiguity associated with discrepant IT events and their motivational incongruity might be directing users to take active strategies in order to overcome the event. Our results support this finding (see Table 2). For example, one user reported actively dealing with connection problems while using Tally 7.2: "Last week it gave a lot of problems with connecting to the server. I checked the configuration of the software and reinstalled the software on my PC" (Participant 238).

Another type of engagement response found is the engagement in help-seeking behaviours (34.40\%). Help-seeking behaviours involve actually dealing with the discrepant event by asking others for support. These help-seeking behaviours are believed to have emerged during evolution as we developed into a social species [35]. Out of the all the help-seeking behaviours, users focused most on seeking instrumental support (82.67\%), either by asking others for help or by looking for help themselves in manuals or online (see Table 2). Furthermore, as users worried about the necessity to attain their goals and the potential negative consequences of the event [54], they were more likely to seek help. As a result:

Proposition 1: When there is a discrepant IT event, users adopt an engagement coping strategy.

\section{Negative Emotions}

There were other related responses that users experienced following a discrepant IT event. Not only did users adopt an engagement strategy, they also experienced negative emotions (in $87.16 \%$ of the cases) when a discrepant IT event took place (see Table 2): "I feel extremely annoyed [referring to a browser] " (Participant 187). This appraisal is at the heart of individuals' emotional experiences [69] and is instrumental in selecting the behavioural response to the event 
[49]. Negative emotions, then, help to classify a discrepant IT event as an undesirable situation: because people respond with greater emotional intensity to events that are seen as 'negative' [78], negative emotions signal that there is something awry with the environment that needs to be dealt with [14].

Interestingly, experiencing negative emotions was not solely or mostly focused on stress responses (stress was only experienced in $5.79 \%$ of the cases in which negative emotions were reported). Although stress is the major emotion described within the original coping theory [49], researchers have argued for the inclusion of different types of (mostly negative) emotions [74]. For example, Engel [22] noted that a wide range negative emotions are part of the coping

process, without stress being a requisite for these. Similarly, Smith and Kirby [74, p. 196] remarked the definition of stress in coping theory is 'overly' restrictive, 'unclear', and 'troublesome' thus, calling for a more inclusive definition of 'emotion' within coping theory. Our results are consistent with such a view. The negative emotion most experienced by users was feeling annoyed (59.47\%), including feeling upset, irritated, and mad, followed by frustration $(48.42 \%)$ (see Table 2). As a result:

Proposition 2.: When there is a discrepant IT event, users experience negative emotions.

\section{Attributions}

Another response to discrepant IT events was attributions for events (83.49\%). Although coping theory does not address attributions, attribution theory (AT) can explain how individuals make causal conjectures about events they encounter [41,42]. Attributions are the causal inferences that individuals associate with particular outcomes or events [41, 42]. People assign causes to events driven by a motivation to "gain and maintain control over the environment" [75, 
p. 283]. Thus, attributions occur due to individuals' needs for self-enhancement, self-protection, positive presentation of self to others [42], and seeking knowledge about their surroundings [41].

Our results show that users blame external factors (e.g., software and other individuals) for discrepant events in $73.85 \%$ of the cases, whereas they blame themselves in only $14.20 \%$ of the cases (see Table 2) For example, after his/her company upgraded to MS Office 2003, a participant reported: "I discovered that 'copying' text, and then 'pasting' it into MS Word, would cause Word to hang, or lock up [...] Okay, what the **** did Microsoft screw up now!" (Participant 62). This indicates that users are likely to engage in external attributions of responsibility following discrepant IT events.

Such results are consistent with AT which explains external attributions via two possible mechanisms: actor-observer bias and self-serving bias. The actor-observer bias (also known as the fundamental attribution error) states that the probability that a person perceives an event or behaviour being driven by internal or external causes depends on his/her role; that is, whether he/she is the actor or the observer of the behaviour [37, 68]. In general, people make external (situational) attributions when they are the actors in a given situation; that is, when they are involved in a situation, they blame situational characteristics (including others) for the event. In contrast, individuals usually make internal (dispositional) attributions when they are observers of a given event; that is, if they are observers of an event in which other people are involved, they are likely to attribute the causes of the event to the involved individuals' personal characteristics [37, 68]. According to Storms [76], the actor-observer bias occurs because the physiology of perceptions shapes the observers' attention towards the actor rather than the situation.

The second explanation for external attribution comes from self-serving biases. Selfserving biases can be defined as individuals' tendencies to make internal attributions when they 
achieve positive outcomes and external attributions when they face negative ones $[33,57,83]$.

This self-serving bias occurs because of individuals' inclination to maintain a positive self-image [83]. Thus, these two types of biases provide a theoretical explanation for the high percentage of external attributions found in the data. Consequently:

Proposition 3: When there is a discrepant IT event, users will engage in attribution assignation, mainly in external attributions.

\section{Dynamicity of the Coping Process}

Dynamicity represents an important part of the coping process [49]. As we will show next, users adjust their coping strategies as the situation evolves over time.

\section{Readjustment of Engagement Strategies}

Earlier we argued that the coping process is dynamic [12, 29, 30, 47, 49]. Coping efforts and their outcomes are evaluated as the situation unfolds [29, 30]. Thus, individuals might engage in one coping strategy and later change to another as a result of the evaluation of previous coping efforts $[47,49]$. This means that the outcomes of the pursued coping strategies will influence users' subsequent appraisals of the situation, which in turn triggers an adjustment of coping mechanisms.

Study results support this adjustment of strategies (see Table 2). For example, one participant explained how s/he modified his/her behavior as follows: "One day the program [Microsoft Share Point] just could not be entered due to power failure which was thought at the time was a computer glitch. The first thing I tried was totally shutting down the program and restating it, it didn't work, next I went on line with live support to help me solve the problem and was informed that it was a connection problem, so I contacted my ISP and was told that they were experiencing technical difficulties" (Participant 167). 
Findings show that such readjustment of engagement coping occurs even when the event is still not resolved. In this case, users still feel they can do something about it; that is, they feel they have other resources to mobilize to continue trying to overcome the event. As a result:

Proposition 4: When the discrepant IT event is not resolved but users feel they have the resources to deal with it, they will adjust their engagement coping.

\section{Disengagement Coping}

As a discrepant IT event unfolds, previous (engagement coping) efforts are assessed and the characteristics of the event become more specific [49]. This allows users to more accurately evaluate whether the event is changeable, and thus, decide whether to switch to an escape strategy (disengagement coping) [49]. As explained earlier, when users feel they have no control over the situation or the skills or surrounding support to overcome it, they adopt a disengagement coping strategy. This allows them to focus on something else, either the current task if possible or something else, which allows them to put the discrepant event out of their minds. Thus, when users see that the previous engagement coping did not eliminate or resolve the discrepant IT event, the available options (resource availability) decrease, and users are more likely to adopt disengagement coping.

This resource availability is called 'controllability' in AT and refers to the extent to which individuals believe they can control and change a given event or situation [82]. Just as resource availability is at the heart of coping theory, controllability is an important concept in AT because one of the motivations for individuals to assign causes to events is to exert control over the environment. For example, AT theory states that situations of low controllability are likely to lead to withdrawal behaviors [82], which is consistent with coping theory. Thus, both AT and coping theory suggest that low controllability or no resource availability are likely to lead to disengagement coping [49, 82]. 
In this study, this appears to have taken place only in $7.80 \%$ of the cases ${ }^{1}$. As an example, a participant reported how s/he could not do anything about the slowness of loading certain software, and thus, adopted disengagement coping: "The Idx software freezes up due to too much volume on the server. Logician software does not load at particular times also do to too many on the server. With these programs there is nothing I can do. I just have to wait for them to clear themselves.." (Participant 220). Thus, when users feel they cannot do anything about the event, they just give up in trying to find a solution for it, thus, adopting a disengagement coping strategy. As a result:

Proposition 5: When the discrepant IT event is not resolved and users feel they do not have the resources to deal with the event, they will adopt disengagement coping.

\section{“Accidental Outcomes": Learning}

Interestingly, our results show that the behaviours users adopt to deal with discrepant events appear to have certain 'accidental' outcomes. For example, users can experience learning in certain situations.

Although learning does not occur often (only in $12.84 \%$ of the cases), users ended up 'accidentally' learning something new in some situations. These learning experiences included learning new application functionality, learning new ways of doing tasks differently, and learning to interact more efficiently with the technology. For example, one participant reported learning while doing some research in order to fix a discrepant IT event: "While clicking around, I noticed some features under a section called 'Debug' and after a little research, found that I could add a marker called a Break Point in the code" (Participant 318).

\footnotetext{
${ }^{1}$ The small number of cases with reported disengagement strategies might be due to the nature of the data. That is, participants were asked to report what they did when the event took place, not to report what they did after the event if they gave up.
} 
The findings show a pattern with respect to the behaviors that are likely to result in learning experiences: users need to adopt an engagement coping strategy for learning to be able to take place. It is either by searching for more information by trial and error, or by asking others for help, that learning might take place. An example in which people sought instrumental support and learning occurred is as follows: "I ran into a problem of figuring out how to create certain functions [...] With the help of my partner, many read throughs of the instructions and patience, I was able to slowly complete the required process to finish my work in the software. Once the steps were complete, I understood what I was supposed to be doing in the beginning and if I had to do it again, I believe that I would know what to do" (Participant 312).

This experiential learning is close to the notion of 'windows of opportunity' described by Tyre and Orlikowski [80]. There are situations (e.g., the introduction of a new system in Tyre and Orlikowski's study) in which learning takes place through experimenting with the system. Similarly, our results show that learning can take place as users try to overcome discrepant IT events. Furthermore, our previous results emphasize the unpredictability of learning in natural settings: errors (such as discrepant IT events) might serve a positive function by enhancing learning in certain situations [32].

This accidental learning is important for two reasons. First, exploration of technology for learning purposes is likely to cease after the first few weeks of use [80]. Later, learning becomes less likely because active efforts imply both a change in habits and an intentional effort [80]. Second, because discrepant IT events trigger intense negative emotions (as described earlier), such negative emotions can facilitate the remembrance in future situations of what is learned during the event. In support of this, recent research suggests that stress facilitates learning when it is experienced near the time when the knowledge acquisition takes place [40] because emotion 
plays an essential role in the creation of memories [3]. Therefore, this 'accidental' learning as a result of discrepant IT events might be very effective for users when confronted with similar situations in the future. In summary, our results show that when there is engagement coping, there are possibilities for learning. As a result:

Proposition 6: When there is engagement coping, learning can take place.

\section{Discussion}

Combining the data gathered in this study with the literature on coping, attribution theory, and learning, we present a model of how users cope with discrepant IT events (see Figure 2).

\section{Figure 2. Theoretical Model}

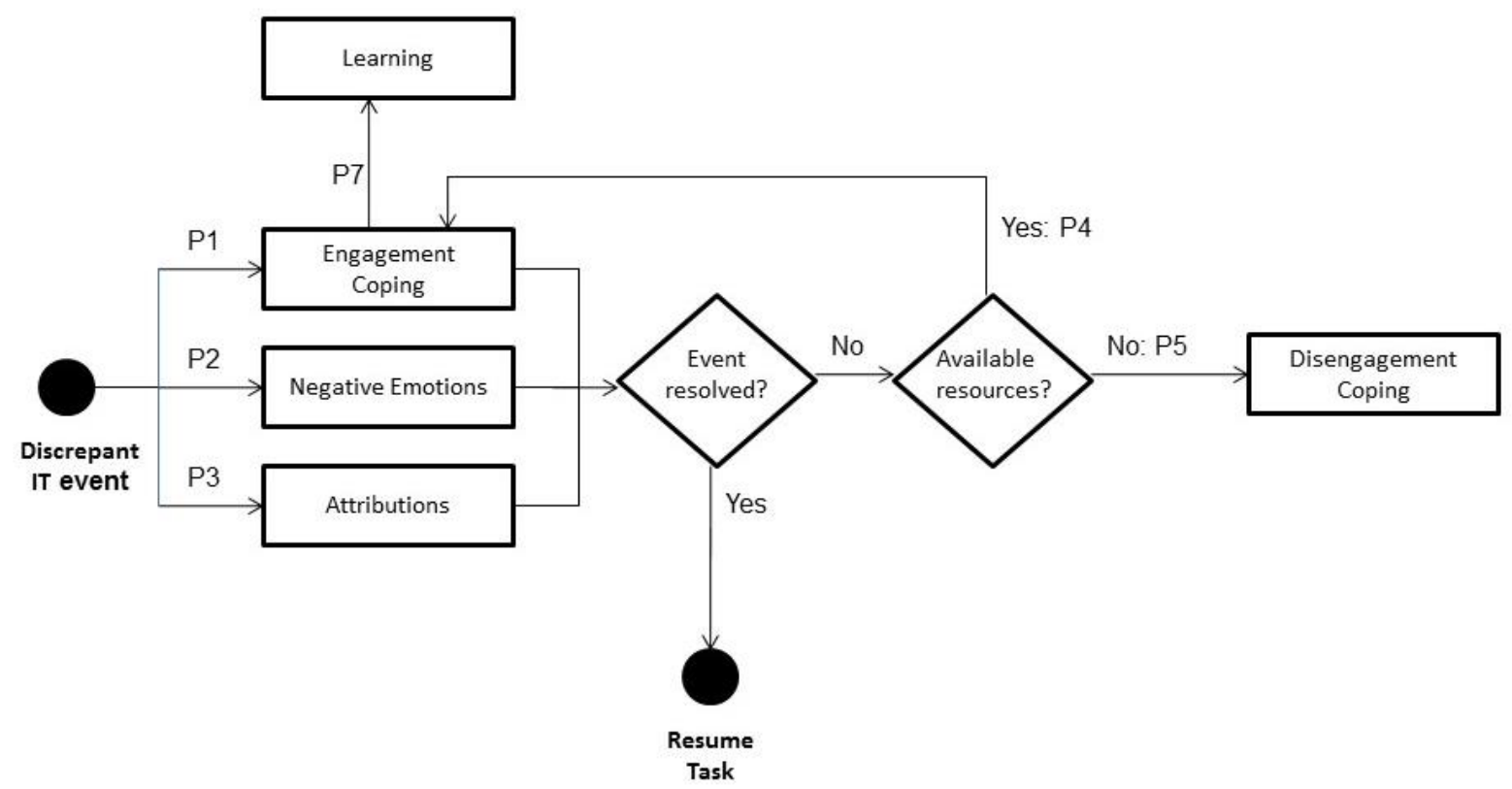

Our pragmatic approach allows us to fine-tune coping theory to the specific case of discrepant IT events and to discover other related processes such as attributions and learning. Although this model provides a rich understanding of the processes by which users deal with discrepant IT events, the temporal sequence implicit in the model warrants further investigation. This is because people sometimes overestimate the intensity and duration of their emotional reactions to past events $[53,84]$. As a result, experimental results were used to validate the proposed model. 


\section{STUDY 2: EXPERIMENT}

A double-blind ${ }^{2}$ experiment was conducted with twelve university students in which their responses to different discrepant IT events were video recorded ${ }^{3}$. This experiment complements the previous method by providing a more detailed account of the temporal sequence of events and processes that are involved in users' responses to discrepant IT events. This approach is in line with recent research highlighting the necessity of conducting longitudinal observations to better understand and disentangle the coping process [64].

The experimental task consisted of students writing an essay about a controversial topic at their university using Microsoft Word. This topic was determined to be appropriate since it had been dealt with openly on campus, had appeared often in the news, and thus it was likely that students would have heard about it and formed their own opinions.

Participants were randomly assigned to one of three experimental conditions. In condition 1, participants experienced three minor discrepant IT events that could be easily overcome (see Table 3). In condition 2, participants were presented with the same discrepant events as in the previous condition but this time it was more difficult for them to address them; however, they could eventually find a way to overcome them. In condition 3, participants had the same discrepant IT events as in conditions 1 and 2, but this time they were unable to resolve the events.

The experiment took place in a private office with the blinds and door closed to minimize distractions. The office was equipped with a desktop computer with Microsoft Word installed on it. Most other programs (such as Internet Explorer) were disabled. Next to the desktop monitor, a

\footnotetext{
${ }^{2}$ The participants and experimental administrators were unaware of the propositions of the study.

${ }^{3}$ The data were randomly drawn from a larger experiment conducted for another research project (Anonymous, forthcoming).
} 
Table 3. Experimental Conditions

\begin{tabular}{|c|c|c|}
\hline $\begin{array}{l}\text { Time of } \\
\text { Experimental } \\
\text { Treatment }\end{array}$ & Condition & Description of Experimental Treatment \\
\hline \multirow[t]{3}{*}{$\begin{array}{l}7 \text { minutes into the } \\
\text { task }\end{array}$} & Condition 1 & $\begin{array}{l}\text { Font automatically changes to } 18 \text { point, } \\
\text { paragraph changes to half space and bullet } \\
\text { points }\end{array}$ \\
\hline & Condition 2 & $\begin{array}{l}\text { The same changes as before, but the } \\
\text { functions to change the format back are } \\
\text { disabled. Participants eventually find a way } \\
\text { to overcome this situation. }\end{array}$ \\
\hline & Condition 3 & $\begin{array}{l}\text { The same changes as before, but the } \\
\text { functions to change the format back are } \\
\text { disabled. Participants never find a way to } \\
\text { overcome this situation. }\end{array}$ \\
\hline \multirow[t]{3}{*}{$\begin{array}{l}15 \text { minutes into the } \\
\text { task }\end{array}$} & Condition 1 & $\begin{array}{l}\text { Font automatically changes to } 16 \text { point and } \\
\text { all capital letters, and paragraph changes to } \\
\text { double space. }\end{array}$ \\
\hline & Condition 2 & $\begin{array}{l}\text { The same changes as before, but the } \\
\text { functions to change the format back are } \\
\text { disabled. Participants eventually find a way } \\
\text { to overcome this situation. }\end{array}$ \\
\hline & Condition 3 & $\begin{array}{l}\text { The same changes as before, but the } \\
\text { functions to change the format back are } \\
\text { disabled. Participants never find a way to } \\
\text { overcome this situation. }\end{array}$ \\
\hline \multirow[t]{3}{*}{$\begin{array}{l}21 \text { minutes into the } \\
\text { task }\end{array}$} & Condition 1 & $\begin{array}{l}\text { Font automatically changes to } 18 \text { point, } \\
\text { paragraph changes to half space and bullet } \\
\text { points }\end{array}$ \\
\hline & Condition 2 & $\begin{array}{l}\text { The same changes as before, but the } \\
\text { functions to change the format back are } \\
\text { disabled. Participants eventually find a way } \\
\text { to overcome this situation. }\end{array}$ \\
\hline & Condition 3 & $\begin{array}{l}\text { The same changes as before, but the } \\
\text { functions to change the format back are } \\
\text { disabled. Participants never find a way to } \\
\text { overcome this situation. }\end{array}$ \\
\hline
\end{tabular}

mirror was placed in which the participant's face was reflected. A video camera was placed behind the participant at the end of the room. Thus, the video camera was able to record the participant from behind, getting a view of his/her back, his/her face on the mirror, his/her hands, the monitor, the mouse, and the keyboard. The camera also recorded the audio for the analyses. 
Participants were asked to 'think aloud' while performing the task in order to follow a protocol analysis methodology. Protocol analysis is a methodology for eliciting verbal reports of thought sequences as a valid source of data on thinking and behaviors [23, 24]. This method posits that it is possible to instruct participants to verbalize their thoughts and behaviors in a manner that does not alter the sequence of thoughts mediating the completion of a task [24].

\section{Coding and Analysis}

The audio from the videos was transcribed by a professional agency. The videos as well as the transcriptions were coded using the same coding sheet as in the previous study. A category representing the time spent in each type of response was also added. As in the previous study, the author and an independent rater coded a subset of the data. Whenever there was a disagreement, both coders would discuss it to reach an agreement. This was done iteratively until the two raters had an inter-rater agreement of .82 , after which, the independent rater coded the rest of the data.

As in the previous study, the unit of analysis was each discrepant IT event. This time, however, it is important to note that discrepant IT events within participants might be related to each other because of personal characteristics. Therefore, discrepant IT events were analyzed within events, across events, and then, within individuals and across individuals [20]. The analyses validated the theoretical saturation found in the previous study because no new categories or themes emerged from the data.

\section{Results}

As shown next, temporal evidence of the propositions is given by three illustrative examples, one for each condition (Table 4). Further, more general support for the propositions is provided in Table 5. Next, we explain these results. 
The results of the experiment corroborate both the propositions and the temporal sequence portrayed in Figure 2 . The findings demonstrate that three responses occurred immediately after discrepant IT events: engagement coping, negative emotions, and attributions. With respect to engagement (Proposition 1), in all occasions in which users were presented with a discrepant event, and regardless of the controllability of the event, they tried to overcome the situation. Furthermore, participants experienced negative emotions (Proposition 2) after the discrepant IT event. Likewise, they made attributions or the assignation of responsibility for the discrepant events (Proposition 3), although this did not occur in all cases (see Tables 4 and 5).

Experimental findings also corroborate the second part of the process model in Figure 2, in which coping efforts are reassessed and modifications to the engagement coping process are made while participants still feel they can change the situation. As users tried different ways to fix the events and still felt they could change the situation, they adjusted their engagement strategies (Proposition 4). For example, if the icons with specific functions in the upper part of Microsoft Word did not work when trying to fix the discrepant events, they then tried to go within the menu options, or they tried to look into the Styles option, or they tried to install new formatting (see Tables 4 and 5).

As additional evidence across the three experimental conditions, the first time users were presented with a discrepant IT event, they spent an average of 97.58 seconds in engagement coping activities (trying to fix the event in one way and trying another if that did not work) directed at dealing with the event (they also spent 61.25 seconds in engagement coping activities after the second event, and 50.50 seconds in engagement coping activities after the third one). Eventually, all the participants in conditions 1 and 2 could overcome the event and resume their tasks. 
Table 4. Experiment: Evidence for Temporal Effects

\begin{tabular}{|c|c|c|c|c|c|}
\hline Time & \multicolumn{2}{|c|}{ Propositions } & 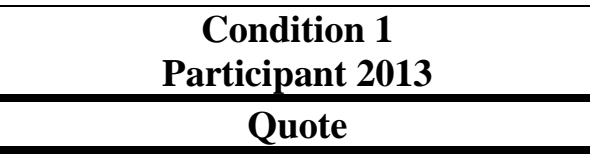 & \begin{tabular}{|c|}
$\begin{array}{c}\text { Condition 2 } \\
\text { Participant 1014 }\end{array}$ \\
Quote \\
\end{tabular} & Condition 3 \\
\hline$\downarrow$ & 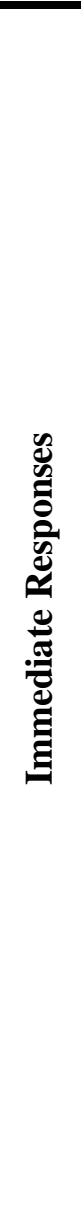 & P1 & $\begin{array}{l}\text { I don't know how I'm supposed } \\
\text { to write right now, I don't want } \\
\text { to do this, ****. [using mouse to } \\
\text { fix issue] Yeah, it's * [speaking } \\
\text { very, very softly] why is this not } \\
\text { like that? [using mouse to fix the } \\
\text { issue] What happened? } \\
\text { [Responding to questions } \\
\text { O0:07:13] [reading, not } \\
\text { speaking, using mouse] } \\
\text { [scratches head] Yeah, so right } \\
\text { now I'm just thinking, like, what } \\
\text { the hell happened to Word. } \\
\text { [smoothes hair] That was really } \\
\text { creepy, but I guess it's the } \\
\text { program and I thought I knew } \\
\text { how to fix everything, but I } \\
\text { obviously can't because } \\
\text { everything is really condensed. } \\
\text { [hand gestures, pointing at } \\
\text { computer] I need to really make } \\
\text { it go back. [smoothes hair] ... I } \\
\text { want to get this fixed. Yes, okay, } \\
\text { so let's go to "font" and... okay, } \\
\text { that's... that looks really weird. }\end{array}$ & $\begin{array}{l}\text { You've got to be kidding me! } \\
\text { Why? Why? Why? Why?.... } \\
\text { [using mouse, trying to fix } \\
\text { document] No, not funny, okay } \\
\text { not funny. I am definitely not } \\
\text { happy Frustrated, yes, } \\
\text { displeased, yes, upset, slightly... } \\
\text { Don't tell me you're not giving * } \\
\text { Oh! I found it. Then why is it... } \\
\text { [trying to fix document] why is it } \\
\text { looking so weird? [reading } \\
\text { sheet, using mouse] Oh! I know } \\
\text { why. That's because oh, shoot! } \\
\text { That is one thing I don't know } \\
\text { about Microsoft. How do I } \\
\text { change this to lower characters? } \\
\text { I wouldn't have taken so much } \\
\text { time if I knew how to do that, but } \\
\text { I don't. So does it mean I have } \\
\text { to write it all over again? Which } \\
\text { is, like, the last thing I want to } \\
\text { do right now. This is definitely, } \\
\text { definitely not cool. [sniffs] } \\
\text { Someone should have taught this } \\
\text { to me, this is not nice }\end{array}$ & $\begin{array}{l}\text { What just happened? Okay, let's deal with } \\
\text { this problem. Nope, zooming out's not } \\
\text { working. Now it just bulleted it. [using } \\
\text { mouse] Okay, bullets not working, let's try } \\
\text { to pick a font... not pleased with my work } \\
\text { [coughs, puts hand to mouth] ... Hopefully I } \\
\text { don't get sick. High, yeah, all right. Let's } \\
\text { try to fix this. So that's that, [using mouse } \\
\text { and keyboard] okay there's a reason it cut } \\
\text { that off, let's fix the margins..." }\end{array}$ \\
\hline
\end{tabular}


Table 4. Continued

\begin{tabular}{|c|c|c|c|c|c|}
\hline \multirow[t]{2}{*}{ Time } & \multicolumn{2}{|c|}{ Propositions } & \multirow{2}{*}{$\begin{array}{c}\text { Condition 1 } \\
\text { Participant 2013 } \\
\text { Quote }\end{array}$} & Condition 2 & \multirow{2}{*}{$\begin{array}{c}\text { Condition 3 } \\
\text { Participant 1021 } \\
\text { Quote } \\
\text { (Support for P4) } \\
\end{array}$} \\
\hline & & & & Quote & \\
\hline & 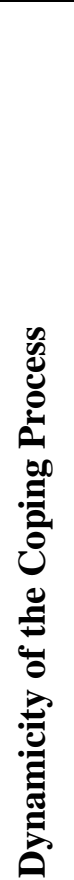 & $\mathbf{P 4}$ & $\begin{array}{l}\text { Yes, okay, so let's go to "font" } \\
\text { and... okay, that's... that looks } \\
\text { really weird. [using mouse, } \\
\text { trying to fix program] I don't } \\
\text { know what's wrong with this. } \\
\text { [scratches arm, exasperated } \\
\text { sigh, leans forward, reading] } \\
\text { Okay, why is the font like that? } \\
\text { It's so stupid. Oh, you know } \\
\text { what, maybe it's in "super } \\
\text { script." Probably not. Okay, } \\
\text { it looks so weird. [smoothes } \\
\text { hair] } \\
\text { Note: Eventually all the } \\
\text { participants in conditions } 1 \\
\text { could overcome the event and } \\
\text { resume their tasks. }\end{array}$ & $\begin{array}{l}\text { Just want to shut up and } \\
\text { really try to figure out... or } \\
\text { call my friend or something } \\
\text { to... okay, installing } \\
\text { formatting } \\
\\
\text { Note: Eventually all the } \\
\text { participants in conditions } 2 \\
\text { could overcome the event } \\
\text { and resume their tasks. }\end{array}$ & $\begin{array}{l}\text { Let's try to fix this. So that's that, [using mouse and } \\
\text { keyboard] okay there's a reason it cut that off, let's fix } \\
\text { the margins. [using mouse] So that's correct. Hmm, } \\
\text { let's change the font back to Normal 12, ...., Times } \\
\text { New Roman, yeah, sure, that works, now go back to } \\
\text { the right there. That's kind of odd, it cuts off the top } \\
\text { part of the lines... oh, I know what happened, I think, } \\
\text { [using mouse] let's check the font. Yeah, so } \\
\text { [untangling mouse] stupid mouse, so we're going to } \\
\text { select all the font and [using mouse] and right click. } \\
\text { Okay, so right click's not working anymore. Font, } \\
\text { okay, woops, undo All right, so I can't really see } \\
\text { what's happened. [leans back, puts hand to chin] } \\
\text { Translate... I want to fix the font". }\end{array}$ \\
\hline$\downarrow$ & & P5 & & & $\begin{array}{l}\text { I want to fix the font. There we go, no, font seems, it } \\
\text { came back up. Character spacing, it's all normal, font } \\
\text { [scratches head] everything normal. Okay, all right, } \\
\text { well, I'll just continue on. [error not fixed, starts } \\
\text { talking about the essay and writing]". }\end{array}$ \\
\hline
\end{tabular}


Table 4. Continued

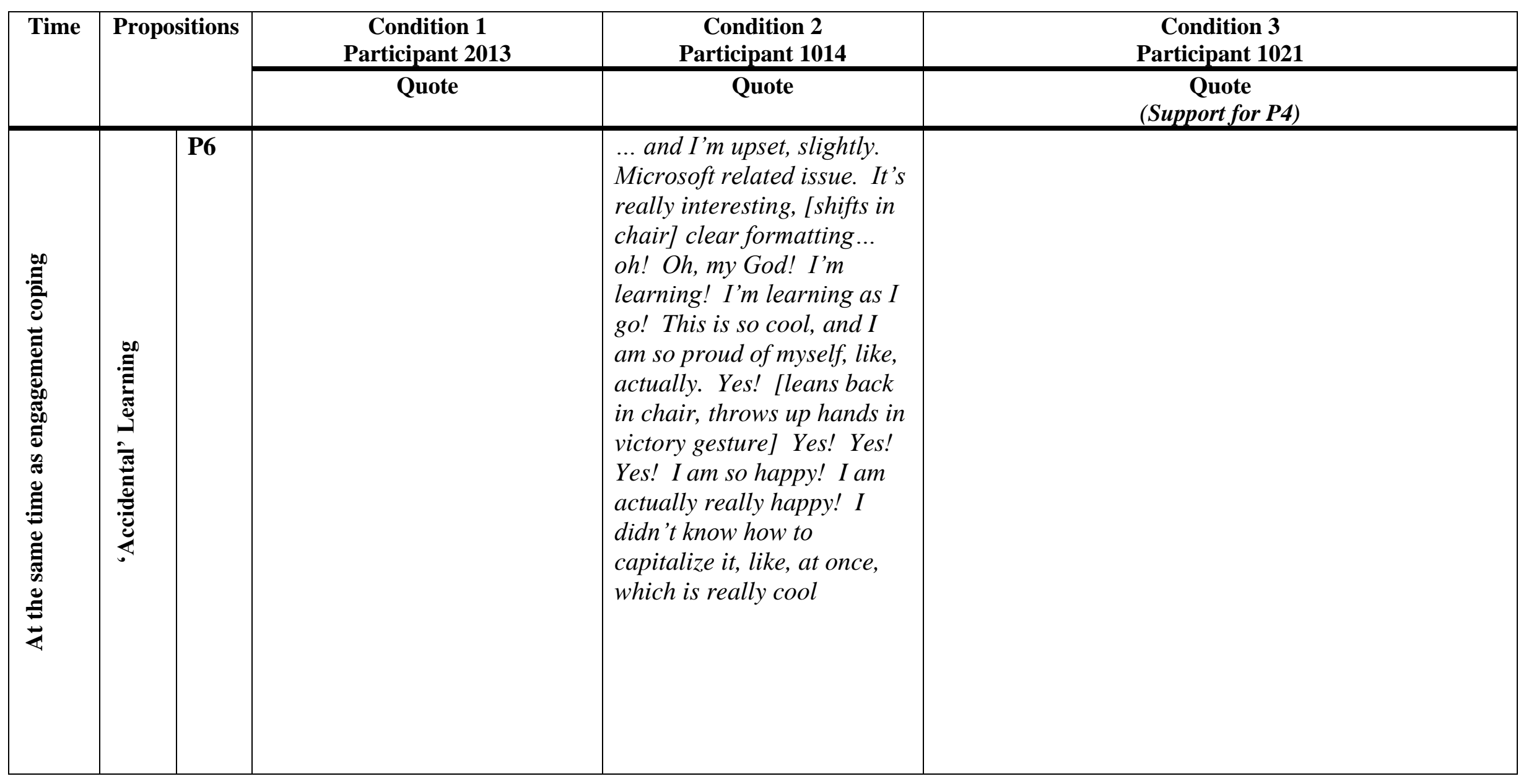




\section{Table 5. Experiment: Evidence for Propositions}

\begin{tabular}{|c|c|c|}
\hline & Propositions & Sample Quotes \\
\hline \multirow{9}{*}{ 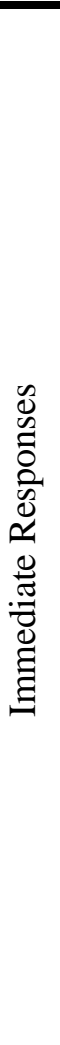 } & \multirow{3}{*}{$\begin{array}{l}\text { P1: When there is a } \\
\text { discrepant IT event, } \\
\text { users adopt an } \\
\text { engagement coping } \\
\text { strategy }\end{array}$} & Times New Roman, paragraph [using mouse] single, excellent (Participant 2045, condition 1) \\
\hline & & $\begin{array}{l}\text { Okay, so all of a sudden it got indented and it got bulleted and the line I put is kind of cutting off. So I'm going to [using } \\
\text { mouse] attempt to fix it and I think } 18 \text { 's too big, but... (Participant 1010, condition 2) }\end{array}$ \\
\hline & & $\begin{array}{l}\text { So I don't really know where the size of the text is, now that I think about it. Font, I guess I'll go to font. now they are } \\
\text { working. [taps mouse] Multiple, no, single, does it tell me which one to use? [reading paper] Times Roman Numeral, } \\
\text { ten point, margins * single I guess, margin, okay. Combination of... oh, this is not } 12 \text { point font. [using mouse, tapping } \\
\text { mouse] And one inch margins, I think, supposed to be point four (Participant 1006, condition 3) }\end{array}$ \\
\hline & \multirow[t]{3}{*}{$\begin{array}{l}\text { P2: When there is a } \\
\text { discrepant IT event, } \\
\text { user experience } \\
\text { negative emotions }\end{array}$} & $\begin{array}{l}\text { What the... ****! [scrolling] Ah, ****, what the hell? [bangs mouse] [throws back head, sighs, stamps feet] [using } \\
\text { mouse, not speaking out loud, sighs] Fuck. Oh, my... [using mouse, trying to fix document] I don't know how to do this. } \\
\text { [shifts in chair] Oh, come on, how am I supposed to fix this? Times New Roman, [clears throat] font, regular, all caps, } \\
\text { there we go. [bangs mouse, heavy sigh] (Participant 2032, condition 1) }\end{array}$ \\
\hline & & $\begin{array}{l}\text { So I'm kind of annoyed that I only see half my work [...] Hmm, so I'm pretty upset [stops typing, leans chin on hand] } \\
\text { with the fact that the words are getting cut off [...] I am pretty frustrated right now (Participant 1010, condition 2) }\end{array}$ \\
\hline & & $\begin{array}{l}\text { What the ****? [using mouse] Are you ******? [using mouse] [leans back, heavy sigh] **** off! [using mouse] } \\
\text { [bangs hard on keyboard] (Participant 1018, condition 3) }\end{array}$ \\
\hline & \multirow{3}{*}{$\begin{array}{l}\text { P3: When there is a } \\
\text { discrepant IT event, } \\
\text { users will engage in } \\
\text { attribution assignation, } \\
\text { mostly in external } \\
\text { attributions }\end{array}$} & $\begin{array}{l}\text { Whoa! What happened! What the...? Shit! Okay, the... [using mouse] ...okay, why is it like this? (Participant 2045, } \\
\text { condition 1) }\end{array}$ \\
\hline & & Why? Why? Why? Why?...(Participant 1014, condition 2) \\
\hline & & Oh, okay, it changed again. Why is it... [using mouse] (Participant 1008, condition 3) \\
\hline
\end{tabular}




\section{Table 5. Continued}

\begin{tabular}{|c|c|c|}
\hline \multicolumn{2}{|c|}{ Propositions } & Sample Quotes \\
\hline \multirow{3}{*}{ 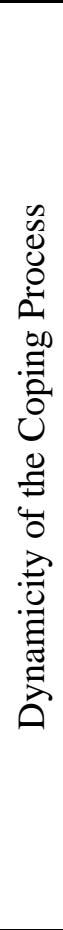 } & \multirow{3}{*}{$\begin{array}{l}\text { P4: When the } \\
\text { discrepant IT event is } \\
\text { not resolved and users } \\
\text { feel they have the } \\
\text { resources to deal with } \\
\text { the event, users will } \\
\text { adjust their } \\
\text { engagement coping }\end{array}$} & $\begin{array}{l}\text { Okay, what if it's something that can't be fixed? Then what am I supposed to do? try fixing the margins, [clears throat] } \\
\text { that should be under "page set-up... I'm just going to continue as is, I think, because I don't know how to fix this." } \\
\text { "Okay, so [using mouse] * it won't get off [taps mouse] so then I go to the main menu and it won 't open. I think a 12, I } \\
\text { think that's what the sheet said. [looking at sheet] Maybe I'll delete this line. [using mouse] Okay, so [00:09:00] the } \\
\text { bullets don't seem to be going away. So I'm trying copy, get rid of it, paste it again. [taps on keyboard, using mouse] Then } \\
\text { I'm going into formatting. Okay, [sits back, sighs] (Participant 2008, condition 1) }\end{array}$ \\
\hline & & $\begin{array}{l}\text { So I'm going to go to format and to bullets and it's not opening, so I'm going to double click. Still not opening, so I'm } \\
\text { going to try and backspace and get rid of them. [using mouse] So... I'm pasting again, I'm trying to keep text only. } \\
\text { [using mouse] Okay, I'm going to highlight it all, [scratches face, leans chin on hand] and go to format go to paragraph } \\
\text { and that should open. [bangs mouse] Okay, so I'm just going to continue writing. [typing] [scratches neck] Hmm, so } \\
\text { I'm pretty upset [stops typing, leans chin on hand] with the fact that the words are getting cut off and I'm trying to look } \\
\text { down at the keyboard and not look up when I type. [scratches arm] [typing] (Participant 1010, condition 2) }\end{array}$ \\
\hline & & $\begin{array}{l}\text { How am I supposed to write it, I can't even read the words, when the top of the words are cut off? And then the paragraph } \\
\text { won't open [taps mouse], we're at Times Roman, I got rid of the bullet, maybe they'll let me get into paragraph now. } \\
\text { Continue to do that, right clicking, not doing it, getting much, much more frustrated. [leans back in chair] Just because I } \\
\text { don't know what to do, if I should continue writing, but how does it make sense to continue writing? [scratches face, hand } \\
\text { gestures, bangs mouse] I can't even read the top of this. I really hope I didn't do that, that I just screwed up this whole } \\
\text { experiment, but... oh, yeah, let me see. [using mouse] I don't know what to do, because when I click on all these buttons, } \\
\text { they're freezing, like, not working, I don't know why I'm getting frustrated about something that doesn't even matter. It's } \\
\text { not school, there we go, now they are working. [taps mouse] Multiple, no, single, does it tell me which one to use? } \\
\text { [reading paper] Times Roman Numeral, ten point, margins, single I guess, margin, okay (Participant 1006, condition 3) }\end{array}$ \\
\hline
\end{tabular}


Table 5. Continued

\begin{tabular}{|c|c|c|}
\hline \multicolumn{2}{|r|}{ Propositions } & Sample Quotes \\
\hline \multirow{2}{*}{ 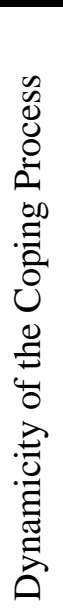 } & \multirow[t]{2}{*}{$\begin{array}{l}\text { P5: When the } \\
\text { discrepant IT event is } \\
\text { not resolved and } \\
\text { users feel they do not } \\
\text { have the resources to } \\
\text { deal with the event, } \\
\text { users will adopt } \\
\text { disengagement } \\
\text { coping. }\end{array}$} & $\begin{array}{l}\text {... oh, ****, okay, [Word problem] so that's really annoying, fine, I don't care. Individuals who hold the events, ..okay, } \\
\text { [smoothes hair] this is annoying, but I just want to finish writing... Okay, so because this is so hard to read, I'm just going } \\
\text { to change it, except... [using mouse] okay, * the way I can see them easily and I just find it a lot easier. Oh, oh, fine it won't } \\
\text { let me change stuff. Okay, let's see if I can add a toolbar in, so I can see the font of a paragraph. Word count, no, * tables } \\
\text { [reading very quietly] okay, so formatting * up here. I have Windows Vista and the new one is a bit different, so this is going } \\
\text { to take me a sec to figure it out again. [smoothes hair] Okay, formatting, okay there we go, paragraph. Oh, okay, apparently } \\
\text { it won't let me change it. So I'm just going to write it like this. That's fine, whatever, I'm going to get started. Okay, so I'll } \\
\text { start with a topic sentence first. [smoothes hair][talks and writes essay] (Participant 1008, condition 3) }\end{array}$ \\
\hline & & $\begin{array}{l}\text { I don't care... this is retarded. [leans forward, shifts in chair] [using mouse, tries to fix Microsoft issues] Now what's } \\
\text { going on? Nope, *** it. [leans back in chair] [pause } 5 \text { sec] [leans back hard in chair, throws up hands] Oh, God! Okay, } \\
\text { [typing, talks about essay] (Participant 1018, condition 3) }\end{array}$ \\
\hline
\end{tabular}


In contrast, in condition 3, this readjustment went on until participants felt they had exhausted all possibilities and could not do anything to change the event (Proposition 5). Participants spent an average of 83.17 seconds (129 seconds after the first discrepant event, 60 seconds after the second discrepant event, and 60.5 seconds after the third discrepant event) in engagement strategies before giving up and adopting a disengagement coping strategy. Thus, there appears to be a critical period of time after which individuals, if they are incapable of fixing the situation and have exhausted the available options, will give up (as Proposition 5 suggests) (see Tables 4 and 5).

Finally, consistent with the first study, learning took place for one participant who adopted an engagement coping strategy ${ }^{4}$ (Proposition 6). In this occasion, the participant was exploring menus for a method to fix the discrepant event and found a solution (i.e., change a chunk of text to lower-case letters at once) that s/he did not know before (see Table 4).

\section{DISCUSSION}

This paper aimed to explain how users cope with discrepant IT events. In order to address this research question, an inductive pragmatic approach was taken. The results of the first study allowed us to fine-tune the conclusions drawn a priori from coping theory, complement them with attribution and learning theories, and develop a model of how users cope with discrepant IT events. This model and its implicit temporal sequence were then validated with experimental results.

Both studies demonstrate that users employ a variety of responses immediately after a discrepant IT event occurs. They experience negative emotions (mostly annoyance and

\footnotetext{
${ }^{4}$ The scarcity of learning in the experiment might be due to the design of the study: participants could not get instrumental support from peers nor online help because the experimental task was individual and the Internet was disabled.
} 
frustration), they adopt engagement coping strategies (mostly active coping and help-seeking behaviours), and they attribute causes to the events (mostly in the form of external attributions). As time passes, individuals adjust their strategies, eventually adopting a disengagement coping strategy when they feel they have no control over the situation (or the necessary resources to address it). Finally, engagement coping strategies aimed at directly dealing with the discrepant IT event can result in the occurrence of 'accidental' learning (mostly as a result of help-seeking behaviours); that is, sometimes individuals learn functionality or ways of doing their tasks with the technology that they did not know before.

This research makes several contributions to the literatures on attributions, coping, learning, and IS. With respect to attribution theory, this research confirms that users are predisposed to make (mostly external) attributions when experiencing a discrepant IT event due to actor-observer and self-serving biases.

With respect to coping, our research shows that discrepant IT events might represent a situation in which secondary appraisal (resource availability) cannot be evaluated until users start trying to fix the event and gather information about it (engagement coping). In the particular case of discrepant IT events, secondary appraisal occurs after engagement coping has started. Further, by using a more mycroanalitic rather than macroanalytic approach, as with the majority of research [47], this paper shows how coping processes are adjusted over time, thus answering calls for research on changing coping strategies as events unfold [47].

Our research also complements the IS learning literature by opening up the possibility that users' learning is not an exclusive outcome of their intentional efforts [e.g., 60], but might also be a byproduct of their 'accidents' during IT interactions. Only a few researchers have highlighted the role of 'errors' in learning: however, they might serve a positive function by 
enhancing learning [e.g., 26, 32, 70]. The results of the first study emphasize that learning as a result of discrepant IT events is more likely to take place when individuals engage in helpseeking behaviors. Future research should be aimed at exploring the situational characteristics (e.g., instrumental support) that might facilitate learning during discrepant IT events.

Although some propose that users are unlikely to continue to learn over time because learning implies an intended effort to change habits [80], our results suggest that learning can take place by 'accident', well after the adoption process has taken place. We suggest that the ‘windows of opportunity' notion proposed by Tyre and Orlikowski [80] can take place during the post-adoption phase as users encounter discrepant IT events and resolve them with engagement coping.

Future research should also refine the dispositional triggers of the spontaneous learning process. For example, past research suggests that learners' goal orientations influence learning processes and outcomes when confronted with discrepant events [31]. Individuals with a mastery orientation are concerned with developing new skills and understanding their task, enjoy challenging tasks [2], and show tolerance for ambiguity [44]. On the other hand, individuals with a performance orientation are likely to believe that ability is fixed, dislike challenging tasks [19], and are less tolerant of ambiguity [44]. It is possible that individuals who reported having learned something did so, in part, because they had high mastery orientations, whereas those who did not report any learning had performance orientations. As a result, future research should be aimed at exploring how individual differences might relate to 'accidental' learning during IT interactions in general, and with discrepant IT events in particular.

With respect to the IS discipline, our research makes several contributions. First, by emphasizing a link between discrepant IT events and behavioral efforts, it goes beyond the nominal 
view of IT [61] and addresses recent calls for theory concerning the direct impact of technology on users' behaviors [62]. Second, by exploring how IT-related situations are assessed, this research helps explain how individuals might form evaluative beliefs about a given IT. Recently, IS scholars have argued for the need to identify the ways cognitive beliefs (e.g., ease of use) about IT are formed [8]. Our model, by driving attention to direct experiences of users with IT, can provide a good theoretical start from which to begin exploring the antecedents of users' cognitive beliefs. For instance, it is possible that certain discrepant IT-related events, along with the emotions, attributions and coping mechanisms they elicit, might lead to the emergence of resistance and avoidance behaviors when repeated over time. Finally, our research also contributes by developing a model that explains actual users' behaviors with IT rather than self-reported use [e.g., 10, 17].

The theoretical model developed in this paper can be assessed against Thorngate's [79] and Weick's [81] classifications of criteria for theory evaluation: accuracy, parsimony, and generality. Given that we identify the regularities in the response processes that are likely to follow a discrepant IT event, our resulting model can provide 'modest' accuracy. Second, theories built based on regularities are likely to be relatively simple and hence, parsimonious [45]. Finally, our model is generic to all users, and future research can further develop and inform it.

\section{Limitations, Strengths, and Future Research}

There are some limitations that should be taken into consideration when interpreting the results of these studies. For example, the nature of the critical incident study did not allow us to capture in-depth qualitative data. In-depth interviews with users about discrepant IT events could help test and refine the propositions developed here. While these limitations do exist and warrant future research, some strengths of these studies are also noteworthy. We examined discrepant IT events as they occurred in real settings without resorting to artificial explanations or scenarios. 
Thus, the realism of the two methods increases the ecological validity of the conclusions. Furthermore, the mixed-method approach helps to overcome the weakness of any single method by compensating one with the strengths of another [39], resulting in a richer understanding of the topic [58].

Apart from future research ideas that have already been presented (i.e., inclusion of learning styles), other avenues for future research are worth noting. For example, other potential individual characteristics, including computer self-efficacy [15] and ability to explore [60], should be considered. It is possible that these individual differences will have an impact on how individuals deal with discrepant IT events, and specifically, 'accidental' learning.

Our model should be extended to include performance effects [e.g., 5]. For example, future research could examine how discrepant IT events and the behavioral and emotional processes associated with them impact personal performance in the short and long runs. Although discrepant IT events might have negative consequences for short-term performance, they could increase performance in the long run as users become familiar with events, learn, and are able to overcome them in a more timely way.

\section{Implications for Practice}

Our model suggests that discrepant IT events can result in users learning previously unknown IT functions or different ways in which to use the IT. Consistently, the education literature mentions the importance of difficult situations and errors for increased learning $[26,70]$. Thus, technological training for users could include tips for managing discrepant IT events to aid users in dealing with future problems and to increase their confidence in their abilities. Furthermore, our research shows that the help-seeking behavioral category of engagement coping is likely to result in learning. As a result, managers should encourage peer support among 
employees for technological-related issues. This will increase the possibilities for learning from discrepant IT events, and might result in better performance when similar events are experienced in the future.

Finally, managers can encourage an environment in which difficulties with IT are seen as opportunities for further learning and educational growth. Recent research supports this approach to learning by specifying the situations under which stress facilitates learning: when it is experienced near the time when the knowledge acquisition takes place [40]. Therefore, managers can emphasize the potential learning outcomes of discrepant IT events, as any knowledge acquisition during their occurrence is likely to be remembered in the future.

\section{Conclusion}

The objective of this paper was to gain an understanding of the ways in which users deal with discrepant IT events. The result is a process model that highlights the dynamicity of the coping process. Our model makes several contributions, such as showing that users appear to only be able to evaluate whether the situation is changeable after they have adopted an engagement coping strategy. More research is needed to link the coping process with performance, and to include individual characteristics as factors affecting the process. 


\section{REFERENCES}

[1] Top tips on... coping with interruptions, in: Professional Manager, 2010, pp. 44-44.

[2] C. Ames, Classrooms: Goals, Structures, and Student Motivation, Journal of Educational Psychology, 84 (1992) 261-271.

[3] A. Anderson, S.W. Draper, An introduction to measuring and understanding the learning process, Computers Education, 17 (1991) 1-11.

[4] H. Barki, R. Titah, C. Boffo, Information System Use-Related Activity: An Expanded Behavioral Conceptualization of Individual-Level Information System Use, Information Systems Research, 18 (2007) 173-192.

[5] A. Basoglu, M. Fuller, Technology mediated interruptions: The effects of task and interruption characteristics on decision-making, in: AMCIS, Keystone, CO, 2007.

[6] A. Beaudry, A. Pinsonneault, IT-Induced Adaptation and Individual Performance: A Coping Acts Model, in: Twenty-Second International Conference on Information Systems, New Orleans, LA, 2001, pp. 475-480.

[7] A. Beaudry, A. Pinsonneault, Understanding User Responses to Information Technology: A Coping Model of User Adaptation, MIS Quarterly, 29 (2005) 493-524.

[8] I. Benbasat, H. Barki, Quo vadis, TAM?, Journal of the Association for Information Systems, 8 (2007) 211-218.

[9] R. Benbunan-Fich, Using Protocol Analysis to Evaluate the Usability of a Commercial Web Site, Inform Manage-Amster, 39 (2001) 151-163.

[10] A. Bhattacherjee, G. Premkumar, Understanding Changes in Belief and Attitude Toward Information Technology Usage: A Theoretical Model and Longitudinal Test, MIS Quarterly, 28 (2004) 229-254.

[11] C.S. Carver, J. Connor-Smith, Personality and coping, Annual Review of Psychology, 61 (2010) 679-704.

[12] C.S. Carver, M.F. Scheier, Situational Coping and Coping Dispositions in a Stressful Transaction, Journal of Personality and Social Psychology, 66 (1994) 184-195.

[13] C.S. Carver, M.F. Scheier, J.K. Weintraub, Assessing Coping Strategies - A Theoretically Based Approach, Journal of Personality and Social Psychology, 56 (1989) 267-283.

[14] R. Centefelli, A. Swarz, Identifying and testing the inhibitors of technology usage intentions, Information Systems Research, 22 (2011) 808-823.

[15] D.R. Compeau, C.A. Higgins, Computer self-efficacy: Development of a measure and initial test, MIS Quarterly, 19 (1995) 189-211.

[16] L. Deng, D.E. Turner, R. Gehling, B. Prince, User experience, satisfaction, and continual usage intention of IT, European Journal of Information Sysetms, 19 (2010) 60-75.

[17] A. Dickinger, M. Arami, D. Meyer, The role of perceived enjoyment and social norma in the adoption of technology with network externalities, European Journal of Information Sysetms, 17 (2008) 4-11.

[18] L. Dubé, G. Paré, Rigor in information systems positivist case research: Current practices, trends, and recommendations, MIS Quarterly, 27 (2003) 597-635.

[19] C.S. Dweck, Leggett, E.L., A Social-Cognitive Approach to Motivation and Personality, Psychological Review, 95 (1988) 256-273.

[20] K.M. Eisenhardt, Building theories from case study research, Academy of Management Review, 14 (1989) 532-330. 
[21] C.M. Elie-dit-cosaque, D.W. Straub, Opening the black box of system usage: User adaptation to disruptive IT, European Journal of Information Sysetms, 20 (2011) 589-607.

[22] B.T. Engel, Stress is a noun! no, a verb! No, an adjective, in: T.M. Field, P.M. McCabe, N. Scheiderman (Eds.) Stress and Coping, Erlbaum, Hillsdale, NJ, 1985, pp. 3-12.

[23] K.A. Ericsson, Valid and Non-Valid Verbalization of Thoughts During Performance of Tasks: Towards a Solution of the Central Problems of Introspection as a Source of Scientific Data, Journal of Consciousness Studies, 10 (2003) 1-18.

[24] K.A. Ericsson, H.A. Simon, Protocol Analysis: Verbal Reports as Data, The MIT Press, Cambridge, MA, 1984.

[25] X. Fang, J. Benamati, A.L. Lederer, Coping with rapid information technology change in difefrent national cultures, European Journal of Information Sysetms, 20 (2011) 560-573.

[26] R. Felder, L. Silverman, Learning and teaching styles in engineering education, Engineering Education, 78 (1988) 674-681.

[27] J.C. Flanagan, The critical incident technique, Psychological Bulletin, 5 (1954) 327-358.

[28] S. Folkman, R.S. Lazarus, An analysis of coping in a middle-aged community sample, Journal of Health and Social Behavior, 21 (1980) 219-239.

[29] S. Folkman, R.S. Lazarus, Coping as a Mediator of Emotion, Journal of Personality and Social Psychology, 54 (1988) 466-475.

[30] S. Folkman, R.S. Lazarus, C. Dunkel-Schetter, A. DeLongis, R.J. Gruen, Dynamics of a stressful encounter: Cognitive appraisal, coping, and encounter outcomes, Journal of Personality and Social Psychology, 50 (1986) 992-1003.

[31] J.K. Ford, E.M. Smith, D.A. Weissbein, S.M. Gully, E. Salas, Relationships of Goal Orientation, Metacognitive Activity, and Practice Strategies with Learning Outcomes and Transfer, Journal of Applied Psychology, 83 (1998) 218-233.

[32] M. Frese, T. Brodbeck, C. Heinbokel, C. Mooser, E. Scheiffenbaum, P. Thiemann, Errors in the Training Computer Skills: On the Positive Function of Errors, Human-Computer Interaction, 6 (1991) 77-93.

[33] D.T. Gilbert, P.S. Malone, The correspondance bias, Psychological Bulletin, 117 (1995) 21 38.

[34] B.R. Golden, The Past is the Past - or Is It? The Use of Retrospective Account as Indicators of Past Strategy, Academy of Management Journal, 35 (1992) 848-860.

[35] F. Gutiérrez, J.M. Peri, X. Torres, X. Caseras, M. Valdés, Three dimensions of coping and a look at their evolutionary origin, Journal of Research in Personality, 41 (2007) 1032-1053.

[36] N. Hamid, A. Lejeune, A model of individual coping with information technology challenges to identity, in: Fifteenth Americas Conference on Information Systems, San Francisco, CA, 2009. [37] F. Heider, Social perception and pehnomenal causality, Psychological Review, 51 (1944) 358374.

[38] J.S. Jasperson, P.E. Carter, R.W. Zmud, A Comprehensive Conceptualization of PostAdoptive Behaviors Associated with Information Technology Enabled Work Systems, MIS Quarterly, 29 (2005) 525-557.

[39] T.D. Jick, Mixing Qualitative and Quantitative Methods: Triangulation in Action, Administrative Science Quarterly, 24 (1979) 602-611.

[40] M. Joëls, Z. Pu, O. Wiegert, M. Oitzl, Krugers, Learning under stress: How does it work?, Trends in Cognitive Sciences, 10 (2005) 152-158.

[41] H.H. Kelley, The processes of causal attribution, American Psychologist, 28 (1973) 107-128. 
[42] H.H. Kelley, J.L. Michela, Attribution theory and research, Annual Review of Psychology, 31 (1980).

[43] H.W. Kim, A. Kankanhalli, Investigating user resistance to information systems implementation: A status quo bias perspective, MIS Quarterly, 33 (2009) 567-582.

[44] M.D. Kroll, Motivational Orientations, Views About the Purpose of Education, and Intellectual Styles, Psychology in the Schools, 25 (1988) 338-343.

[45] A. Langley, Strategies for Theorizing from Process Data, The Academy of Management Review, 24 (1999) 691-710.

[46] J. Lazar, A. Jones, B. Shneiderman, Workplace user frustration with computers: An exploratory investigation of the causes and severity, Behaviour and Information Technology, 25 (2006) 239-251.

[47] R.S. Lazarus, Coping Theory and Research: Past, Present, and Future, Psychosomatic Medicine, 55 (1993) 234-247.

[48] R.S. Lazarus, Emotions and interpersonal relationships: toward a person-centered conceptualization of emotions and coping, Journal of Personality, 74 (2006) 9-46.

[49] R.S. Lazarus, S. Folkman, Stress, appraisal and coping, Springer Publishing Company, Inc., New York, NY, 1984.

[50] R.S. Lazarus, S. Folkman, Transactional theory and research on emotions and coping, European Journal of personality, 1 (1987) 141-169.

[51] H. Lee, S.Y. Choi, Y.S. Kang, Formation of e-satisfaction and repurchase intention: Moderating roles of computer self-efficacy and computer anxiety, Expert Systems with Applications, 36 (2008) 7848-7859.

[52] Y. Lee, K.R. Larsen, Threat or coping appraisal: determinants of SMB executies' decision to adopt anti-malware software, European Journal of Information Sysetms, 18 (2009) 177-187.

[53] L.J. Levine, M.A. Safer, Sources of Bias in Memory for Emotions, Current Directions in Psychological Science, 11 (2002) 169-173.

[54] H. Liang, Y. Xue, Avoidance of Information Technology Threats: A Theoretical Perspective, MIS Quarterly, 33 (2009) 71-90.

[55] J.A. Litman, The COPE inventory: Dimensionality and relationships with approach- and aovidance-motives and positive and negative traits, Personality and Individual Differences, 41 (2006) 273-284.

[56] E. Malmberg, Cutting the costs of technical support, in: Infromation Communication Technology Asia, 2009.

[57] A.H. Mezulis, L.Y. Abramson, J.S. Hyde, B.L. Hankin, IS there a universal positivity bias in attributions? A meta-analytic review of individual, developmental, and cutlural differences in the self-selving attributional bias, Psychological Bulletin, 130 (2004) 711-747.

[58] J. Mingers, Combining IS Research Methods: Towards a Pluralist Approach, Information Systems Research, 12 (2001) 240-259.

[59] M.M. Moore, Rage against the machine: Why do we love to complain about technology? It is fear, anger or just plain stress, in: Darwin, 2002, pp. 56-60.

[60] S. Nambisan, R. Agarwal, M. Tanniru, Organizational Mechanisms for Enhancing User Innovation in Information Technology, MIS Quarterly, 23 (1999) 365-395.

[61] W.J. Orlikowski, C.S. Iacono, Research commentary: Desperately seeking the "IT" in IT research - A call to theorizing the IT artifact, Information Systems Research, 12 (2001) 121-134. 
[62] A. Ortiz de Guinea, M.L. Markus, Why Break the Habit of a Lifetime? Rethinking the Roles of Intention, Habit, and Emotion in Continuing Information Technology Use, MIS Quarterly, 33 (2009) 433-444.

[63] A. Ortiz de Guinea, J. Webster, An investigation of Information Systems use patterns: technological events as triggers, the effects of time, and consequences for performance, MIS Quarterly, 37 (2013) 1165-1188.

[64] M. Oxlad, L. Miller-Lewis, T.D. Wade, The measurement of coping responses: Validity of the Billings and Moos Coping Checklist, Journal of Psychosomatic Research, 57 (2004) 477-484. [65] I.L. Parlin, C. Chooler, The Structure of Coping, Journal of Health and Social Behavior, 19 (1978) 2-21.

[66] R.F. Piccolo, J.A. Colquitt, Transformational Leadership and Job Behaviors: The Mediating Role of Core Job Characteristics, Academy of Management Journal, 49 (2006) 327-340.

[67] J.J. Po-An Hsieh, W. Wang, Explaining employees' extended use of complex inforamtion systems, European Journal of Information Sysetms, 16 (2007) 216-227.

[68] L. Ross, The intuitive psychologist and his shortcomings: Distortions in the attribution process, Advances in Experimental Social Psychology, 10 (1977) 385-397.

[69] T.R. Schneider, Evaluations of stressful transactions: What's in an appraisal?, Stress and Health, 24 (2008) 151-158.

[70] M.K. Sein, R. Santhanam, Research Report. Learning from Goal-Directed Error Recovery Strategy, Information Systems Research, 10 (1999) 276-185.

[71] A. Serenko, A. Stach, The impact of expectation disconfirmation on customer loyalty and recommendation behavior: Investigating online travel and tourism services, Journal of Information Technology Management, (2009).

[72] D.A. Shepherd, K.M. Sutciliffe, Inductive top-down theorizing: A source of new theories of organization, Academy of Management Review, 36 (2011) 361-380.

[73] E.A. Skinner, K. Edge, J. Altman, H. Sherwood, Searching for the structure of coping: A review and critique of category systems for classifying ways of coping, Psychological Bulletin, 129 (2003) 216-269.

[74] C.A. Smith, L.D. Kirby, The Role of Appraisal and Emotion in Coping and Adaptation, in: R.J. Contrada, A. Baum (Eds.) Handbook of Stress Science: Biology, Psychology, and Health, Springer, New York, NY, 2010, pp. 195-208.

[75] C.M. Steele, The psychological of self-affirmation: Sustaining the integrity of the self, in: L. Berkowitz (Ed.) dvances in experimental social psychological, Academic Press, San Diego, CA, 1988, pp. 261-302.

[76] M. Storms, Videotape and the attribution process: Reversing actors' and observers' points of view, Journal of personality an Social Psychology, 27 (1973) 165-175.

[77] S. Tams, S. Hill, A. Ortiz de Guinea, J. Thatcher, V. Grover, NeuroIS- Alternative or complement to existing methods? Illustrating the holistic effects of neuroscience and self-reported data in the context of technostress research, Journal of the Association for Information Systems, 15 (2014) 723-753.

[78] S.E. Taylor, Asymmetrical effects of positive and negative events: The mobilizationminimization hypothesis, Psychological Bulletin, 110 (1991) 67-85.

[79] W. Thorngate, Possible Limits on a Science of Social Behavior, in: J.H. Strickland, F.E. Aboud, K.J. Gergen (Eds.) Social Psychology in Transition, Plenum, New York: NY, 1976, pp. 121-139. 
[80] M.J. Tyre, W.J. Orlikowski, Windows of opportunity: Temporal patterns of technological adaptation in organizations, Organization Science, 5 (1994) 98-118.

[81] K. Weick, The Social Psychology of Organizing, Addison-Wesley, Reading, MA, 1979.

[82] B. Weiner, An attributional theory of achievement motivation and emotion, Psychological Review, 92 (1985) 548-573.

[83] B. Weiner, Human Motivation: Metaphors, Theories and Research, Sage Publications., Thousand Oaks, CA, 1992.

[84] T.D. Wilson, J. Meyers, "How Happy Was I, Anyway?" A Retrospective Impact Bias, Social Cognition, 21 (2003) 421-446. 